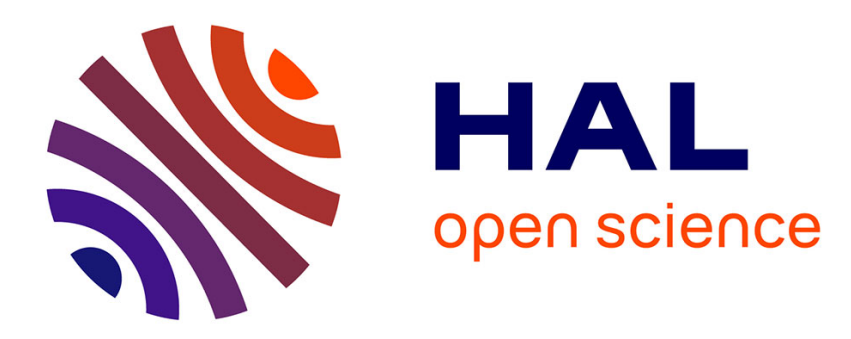

\title{
Effects of drought stress on growth and yield of barley
}

Nezar H. Samarah

\section{To cite this version:}

Nezar H. Samarah. Effects of drought stress on growth and yield of barley. Agronomy for Sustainable Development, 2005, 25 (1), pp.145-149. hal-00886257

\section{HAL Id: hal-00886257 https://hal.science/hal-00886257}

Submitted on 1 Jan 2005

HAL is a multi-disciplinary open access archive for the deposit and dissemination of scientific research documents, whether they are published or not. The documents may come from teaching and research institutions in France or abroad, or from public or private research centers.
L'archive ouverte pluridisciplinaire HAL, est destinée au dépôt et à la diffusion de documents scientifiques de niveau recherche, publiés ou non, émanant des établissements d'enseignement et de recherche français ou étrangers, des laboratoires publics ou privés. 


\title{
Effects of drought stress on growth and yield of barley
}

\author{
Nezar H. SAMARAH* \\ Department of Crop Production, Jordan University of Science and Technology (JUST), Irbid PO Box 3030, 22110, Jordan
}

(Received 28 July 2003; accepted 5 November 2004)

\begin{abstract}
Barley (Hordeum vulgare) grown in Mediterranean regions undergoes drought stress during the grain-filling period. A greenhouse experiment was conducted to study the effect of drought stress on grain growth and yield of barley. Plants were exposed to three drought treatments at the beginning of grain filling: (1) well-watered at 100\% field capacity, (2) mild drought stress at 60\% field capacity, and (3) severe drought stress at $20 \%$ field capacity until grain maturity. Grain moisture content and dry weight were determined for grains harvested at 3,10 , 17,23 and 31 days after the beginning of grain filling. Grain dry weight for severe drought stress plants reached a maximum value earlier than grains from mild drought stress and well-watered plants, indicating that grains from severe drought stress plants had a higher growth rate than those of mild drought stress and well-watered plants. Drought-stressed plants had shorter duration of grain filling than well-watered plants. Drought stress treatments reduced grain yield by reducing the number of tillers, spikes and grains per plant and individual grain weight. In conclusion, postanthesis drought stress was detrimental to grain yield regardless of the stress severity.
\end{abstract}

Hordeum vulgare / drought tolerance / beginning of grain filling / grain maturity / grain development

\section{INTRODUCTION}

Prolonged periods of drought stress resulted in major losses in grain yield of rainfed crops in Jordan, which is characterized by a semi-arid Mediterranean climate where rain is scarce, irregularly distributed, and variable from one year to another [9]. Barley is a main crop grown in these regions because it is adapted to a severe water regime compared with other cereals $[10,19,24]$. However, its productivity is limited by terminal drought stress during grain filling [19]. Barley response to drought stress at this critical stage of development needs to be studied to understand adaptation of barley plants to postanthesis drought stress. Whether severity of postanthesis drought stress is a determinant factor for grain yield needs to be studied. Such information is important for plant breeders to select traits for drought tolerance and for farmers for better crop management, to avoid the occurrence of a drought period at the critical stages of development.

The effects of late drought stress on grain growth and yield have been studied in cereal crops $[10,13,14]$. Drought stress during the grain-filling period decreased the net photosynthetic rate of the flag leaf of barley, but had no significant effect on the grain-filling rate under high vapor pressure deficit [19]. The flag leaf and ear are the main photosynthetic organs to provide assimilates for grain filling, particularly in environments where drought is encountered at the end of the plants' life cycle $[5,6$,
19]. The capacity to remobilize vegetative reserves seems to be responsible for maintaining the grain growth rate under drought stress [18]. Middle to late drought stress advanced leaf senescence, shortened the grain-filling period, and decreased grain yield and individual grain weight of barley [10, 14, 19, 24].

Effects of drought stress at different growth stages of barley have been studied [2, 3, 25]. These studies indicated that drought stress was more sensitive during and just before spike emergence. Another peak of barley sensitivity to drought was during anthesis and the initial stages of grain development. The severity of drought stress from the beginning of grain filling to maturity may be detrimental to grain development (grain abortion) and yield. Postanthesis drought stress may decrease the fertility of late-formed tillers and whether these late-formed tillers contribute to grain number and yield of barley needs to be studied. The objective of this experiment was to study the effect of the severity of drought stress during the seed-filling period on grain growth, duration of grain filling, and grain yield and yield components of barley.

\section{MATERIALS AND METHODS}

A greenhouse experiment was initiated at Jordan University of Science and Technology, Irbid, Jordan on November 18, 2001. Twelve seeds of the barley (Hordeum vulgare) cultivar

\footnotetext{
* Corresponding author: nsamarah@ just.edu.jo
} 
Table I. Plant water consumption during treatment period, photosynthetic active radiation (PAR), leaf quantum yield of light reaction ( $\Phi$ p), leaf photosynthetic rate $(\mathrm{P})$ and leaf osmotic potential at 15 days after beginning of treatment for barley plants exposed to three drought stress treatments imposed from the beginning of grain filling to grain maturity.

\begin{tabular}{lccccc}
\hline Treatments & Plant water consumption & PAR & $\Phi p$ & P & Osmotic potential \\
\hline & Liter/plant & $\mu \mathrm{mol} \mathrm{m}^{-2} \mathrm{~s}^{-1}$ & $\%$ & $\mu$ mol PAR m ${ }^{-2} \mathrm{~s}^{-1}$ & \\
& & & & & \\
Well-watered & $5.63 \mathrm{a}^{\dagger}$ & $605 \mathrm{a}$ & $44 \mathrm{a}$ & $264 \mathrm{a}$ & $-1.23 \mathrm{a}$ \\
Mild stress & $2.27 \mathrm{~b}$ & $751 \mathrm{a}$ & $30 \mathrm{~b}$ & $229 \mathrm{ab}$ & $-1.45 \mathrm{~b}$ \\
Severe stress & $0.94 \mathrm{c}$ & $688 \mathrm{a}$ & $25 \mathrm{~b}$ & $172 \mathrm{~b}$ & $-1.58 \mathrm{~b}$ \\
\hline
\end{tabular}

$\dagger$ Treatment means followed by the same letter indicate no significant difference according to the Least Significant Difference (LSD) test at probability level 0.05 .

"Rum" were planted in 6-L pots containing a mixture of soil: sand: peat in a volume ratio of $2: 1: 1$. Rum originated from Harbin-Arivat X Attik in CIMMYT (Mixico) and was certified in the National Center for Agriculture Research and Technology Transfer (NCARTT), Jordan in 1986. It is six-row barley, medium in height, with high tillering capacity, early to medium in heading and ripening, and produces a large seed size. Before planting, the field capacity of the pots was determined by saturating the soil with water. The pots were covered with plastic sheets and left to drain for $3 \mathrm{~d}$. Pot weights were recorded after $3 \mathrm{~d}$ of drainage. The weight of soil moisture at field capacity was calculated as the difference between the soil weight after drainage and soil weight after oven drying for $105^{\circ} \mathrm{C}$ for $24 \mathrm{~h}$. Three weeks after planting, the seedlings were thinned to six seedlings per pot. The plants were well watered (maintained at field capacity) until they reached the beginning of the linear seed-filling period (spikes on main stem with grains of $3 \mathrm{~mm}$ length). At the beginning of the grain-filling period (on March 10), three drought stress treatments were imposed on the plants: $100 \%$ field capacity (well-watered), $60 \%$ field capacity (mild stress), and $20 \%$ field capacity (severe stress). Drought treatments were imposed from the beginning of grain filling to grain maturity by weighing pots daily and maintaining them at the desired soil moisture content. Two pots were used for each experimental unit.

Drought intensity was quantified by measuring plant water consumption during the treatment period, leaf quantum yield of light reaction, photosynthetic rate and osmotic potential. Plant water consumption was measured from the beginning of grain filling to grain maturity by weighing pots daily before and after irrigation and recording the difference in weight. Photosynthetic active radiation (PAR) and quantum yield of the light reaction $(\Phi p)$ were measured at 15 days after imposing treatments (on March 25) using a Plant Photosynthesis Meter (EARS, Netherlands). The photosynthetic rate $(\mathrm{P})$ can be expressed as the amount of radiation used for photosynthesis per second by:

$$
\mathrm{P}=\Phi \mathrm{p} * \mathrm{PAR}
$$

Leaf osmotic potential was measured at 15 days after treatments for two leaves sampled from the upper part of the plant canopy, packed into a $1-\mathrm{ml}$ syringe, and frozen at -80 for 24 hours, then thawed for 30 minutes. Leaf sap was extracted from the leaf sample by depressing the syringe plunger [23]. Osmotic potential was measured on $10 \mu \mathrm{l}$ leaf sap using a Wescor-5500 Vapor Pressure.

A random sample of spikes from plants exposed to the three drought stress treatments were harvested at 3, 10, 20, 17, 24 and 31 days after beginning the treatments to measure grain dry weight and moisture content. Grain dry weight and moisture content were measured for five random de-hulled grains taken from the middle of harvested spikes.

Grain-filling duration was defined as the period from the beginning of the grain-filling period (main stem spikes with 3-mm grains) to grain physiological maturity (yellow spikes).

At harvest maturity (grain moisture content less than $150 \mathrm{~g} \mathrm{~kg}^{-1}$ fresh weight), 12 plants in each experimental unit were hand-harvested to measure yield and yield components. Number of total spikes, fertile spikes (spikes with grains), sterile spikes (spikes with sterile grains), tillers (including main stem), grains, and total grain weight were recorded for the harvested plants. Data were expressed as a number per plant.

The experimental design was a randomized complete block design with four replications. Data were analyzed using the SAS Program [20]. Means were separated according to the Least Significant Difference (LSD) test at probability level 0.05 .

\section{RESULTS AND DICUSSION}

\subsection{Quantification of drought stress}

Drought intensity was quantified by measuring plant water consumption during the treatment period, leaf photosynthetic active radiation (PAR), quantum yield of light reaction, photosynthetic rate, and osmotic potential (Tab. I). Water consumption of well-watered plants during the treatment period was significantly higher (5.63 liters plant ${ }^{-1}$ ) than the water consumption of mildly- and severely-stressed plants (2.27 and 0.94 liters plant $^{-1}$, respectively). As drought stress intensity increased, water consumption by the plants significantly decreased. Photosynthetic active radiation (PAR) measurements were not significantly different between treatments, indicating that plants were exposed to similar light intensity. Quantum yield, photosynthetic rate and leaf osmotic potential decreased as drought 
stress increased. Drought stress reduced the net leaf photosynthetic rate, leaf transpiration rate and leaf water potential [19]. Wild barley genotypes that came from areas with low water availability had greater osmotic adjustment capacity and greater response to drought stress [11]. In our study, severelystressed plants did not differ in photosynthetic rate and leaf osmotic potential from mildly-stressed plants, indicating that both treatments were detrimental to plant physiological processes. Our data suggest that the quantum yield of light reaction was a useful tool to quantify occurrence and intensity of drought stress in barley. The use of chlorophyll fluorescence from intact, attached leaves proved to be a reliable, nondestructive method in physiological studies [21] and has been extensively used for assessing barley response to heat stress [16], salt stress [4], chilling tolerance [12] and water stress [15].

\subsection{Grain development and filling duration}

Grain moisture content decreased steadily from $608 \mathrm{~g} \mathrm{~kg}^{-1}$ fresh weight at day 10 to $338 \mathrm{~g} \mathrm{~kg}^{-1}$ fresh weight at day 31 (Fig. 1). Drought stress treatments had no effect on grain moisture content except for severely-stressed plants harvested at day 17 , which had significantly lower grain moisture content than mildly-stressed and well-watered plants. Grain dry weight increased as the grain matured. Grain dry weight of severelystressed plants attained a maximum value earlier (at day 17) than mildly-stressed and well-watered plants. Higher grain dry weight of the severely-stressed plants at day 17 suggests that the reduction in grain moisture content of the severely-stressed plants on this sampling date was most likely due to fastening the grain maturity under drought rather than the loss in grain moisture content. At day 31, individual grain weight of well-watered plants was higher than individual grain weight of mildly- and severely-stressed plants. The duration of the grain-filling period supported the grain dry weight data and indicated that as drought stress intensity increased, grain-filling duration decreased (crop matured earlier) (Tab. II). Our data were consistent with other reports on soybean [22], pea [17] and corn [26], which showed that drought stress during seed filling had no effect on seed growth rate but decreased seed-filling duration and individual seed weight. Earliness in barley is an advantageous trait in conditions of terminal drought stress in Mediterranean environments $[1,7,8,10]$. High potential yield and osmotic adjustment may also contribute to increased stress tolerance under such conditions [10].

\subsection{Grain yield and yield components}

Drought stress treatments during grain filling significantly decreased grain yield and yield components (Tab. II). Wellwatered plants had a significantly higher grain yield than mildly-stressed and severely-stressed plants. Mildly-stressed plants were not significantly different in grain yield from severely-stressed plants. Well-watered plants had a higher number of fertile spikes and grains per plant than mildlystressed and severely-stressed plants. Mildly-stressed plants were not different in the number of fertile spikes and grains per plant from severely-stressed plants. Mildly-stressed plants had a higher number of sterile spikes than well-watered and severely-stressed plants. Number of grains per spike was not
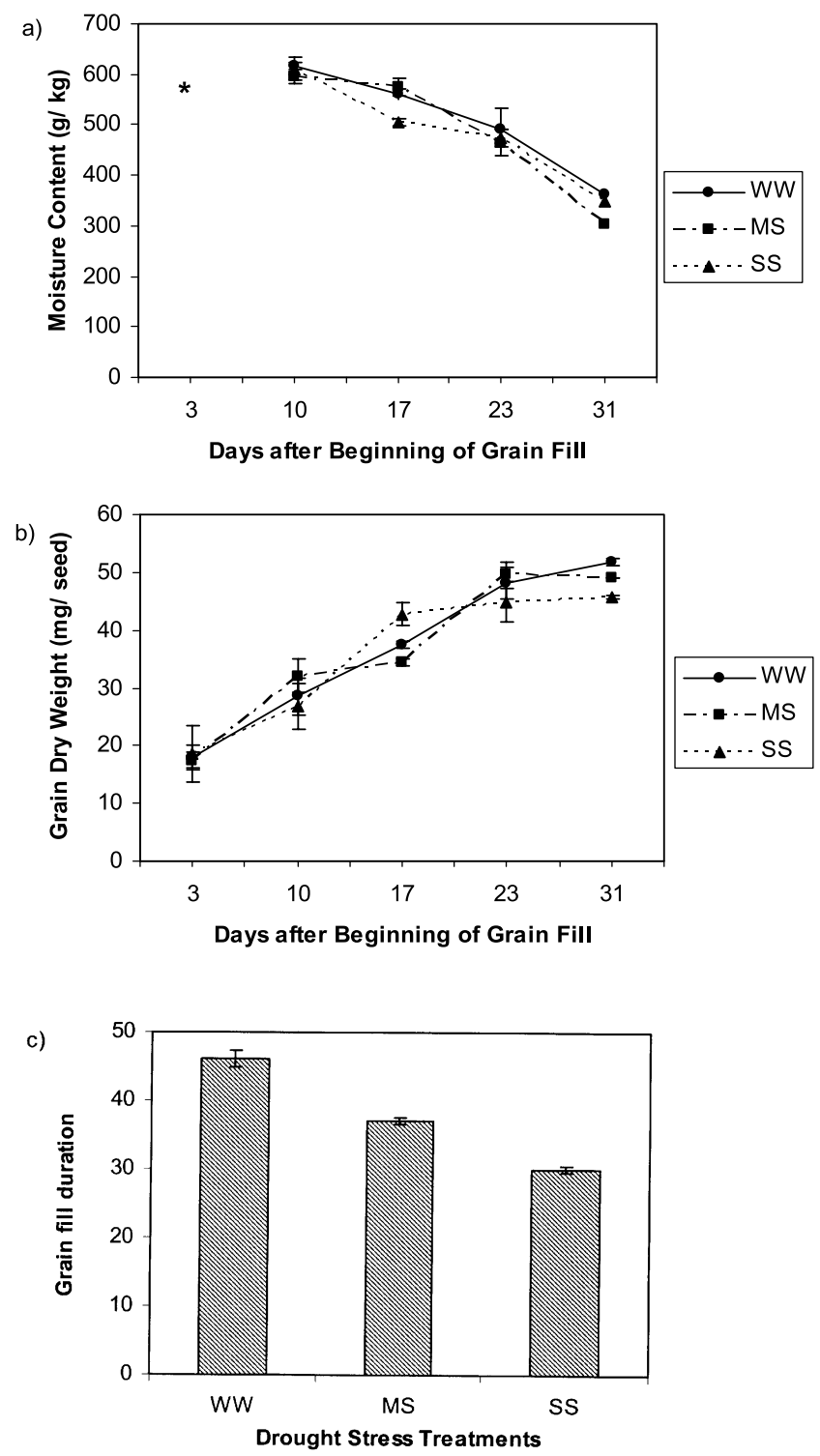

Figure 1. (a) Grain moisture content, (b) grain dry weight, and (c) grain-filling duration for barley plants exposed to three drought treatments from the beginning of grain filling to grain maturity. WW: wellwatered treatment; MS: mild drought stress; SS: severe drought stress. Bars indicate the standard error of the mean. *: missing data at day 3 .

significantly different between treatments. Number of tillers per plant was significantly higher for well-watered and mildlystressed plants than severely-stressed plants.

The results of grain yield and yield components indicated that drought stress treatments during the grain-filling period reduced grain yield by decreasing the number of fertile spikes and grains per plant. Late drought stress decreased grain yield by decreasing the number of grains per ear and grain weight [10]. In our experiment, well-watered plants produced more tillers and consequently more fertile spikes and grains compared with severely-stressed plants. Mildly-stressed plants 
Table II. Yield and yield components, numbers of tillers (including main stem) for barley plants exposed to drought stress treatments imposed from the beginning of grain filling to grain maturity.

\begin{tabular}{|c|c|c|c|c|c|c|}
\hline \multirow[t]{3}{*}{ Treatments } & \multirow[t]{3}{*}{ Grain yield } & \multicolumn{4}{|c|}{ Yield components } & \multirow[t]{3}{*}{ Tillers /plant } \\
\hline & & \multirow{2}{*}{$\begin{array}{c}\text { Grain } \\
\text { number }\end{array}$} & \multicolumn{2}{|c|}{ Spike number } & \multirow{2}{*}{$\begin{array}{l}\text { Grain } \\
\text { /spike }\end{array}$} & \\
\hline & & & Fertile & Sterile & & \\
\hline & $\mathrm{g} \mathrm{plant}^{-1}$ & \multicolumn{3}{|c|}{-------------No. plant ${ }^{-1}$------------ } & No. & No. \\
\hline WW & $16.0 \mathrm{a} \dagger$ & $302 \mathrm{a}$ & $14 \mathrm{a}$ & $5 \mathrm{a}$ & $21 \mathrm{a}$ & $24 \mathrm{a}$ \\
\hline MS & $8.1 \mathrm{~b}$ & $164 \mathrm{~b}$ & $7 \mathrm{~b}$ & $8 \mathrm{~b}$ & $22 \mathrm{a}$ & $24 \mathrm{a}$ \\
\hline SS & $6.9 \mathrm{~b}$ & $137 \mathrm{~b}$ & $7 \mathrm{~b}$ & $3 \mathrm{a}$ & $20 \mathrm{a}$ & $18 \mathrm{~b}$ \\
\hline
\end{tabular}

$\dagger$ Treatment means followed by the same letter indicate no significant difference according to the Least Significant Difference (LSD) test at probability level 0.05 .

were significantly different in the number of tillers from wellwatered plants, but these tillers produced sterile spikes. Mildlystressed plants were not significantly different in the total grain yield from severely-stressed plants. These results indicated that prolonged drought stress during grain filling was detrimental to grain yield regardless of stress severity (mild or severe) and this reduction was mainly due to a reduction in the number of tiller-bearing fertile spikes and grains. Aborted ears greatly attributed to the reduction of grain yield in barley [19]. In our experiment, late-formed tillers significantly contributed to more fertile spikes and total grain yield under well-watered conditions compared with terminal drought stress treatment.

\section{CONCLUSION}

Drought stress during the grain-filling period did not lower grain moisture content, but shortened the grain-filling period and reduced yield. Grains from severely-stressed plants reached maximum weight earlier than well-watered plants and had lower individual grain weight. Severely-stressed plants had shorter duration of grain filling than well-watered plants. These results indicate that the high rate and shorter duration of grain filling under severe drought stress conditions may be important adaptive responses to drought stress. Prolonged mild or severe drought stress from the beginning of grain filling to grain maturity reduced grain yield. Cultural practices that avoid plant exposure to postanthesis drought may decrease the losses in grain yield. Screening barley cultivars for grain-filling rate and duration under terminal drought stress is needed to evaluate drought escape in barley grown under such conditions.

Acknowledgements: Special appreciation is extended to the Deanship of Scientific Research at JUST for financial support. Thanks are also extended to Dr. Juma Amyra for helping with leaf photosynthesis measurements. Thanks to A. Abu-A'an, H. Abu-Ra'a and A. Yameen for technical assistance.

\section{REFERENCES}

[1] Acevedo E., Craufurd P.Q., Austin R.B., Pérez-Mcrco P., Traits associated with high yield in barley in low-rainfall environments, J. Agr. Sci. 116 (1991) 23-36.
[2] Aspinall D., The effects of soil moisture stress on the growth of barley: II. Grain Growth, Aust. J. Agr. Res. 16 (1965) 265-275.

[3] Aspinall D., Nicholls P.B., May L.H., The effects of soil moisture stress on the growth of barley: I. Vegetative development and grain yield, Aust. J. Agr. Res. 15 (1964) 729-745.

[4] Belkhodja R., Morales F., Abadía A., Medrano H., Abadía J., Effects of salinity on chlorophyll fluorescence photosynthesis of barley (Hordeum vulgare L.) grown under a triple line source sprinkler system in the field, Photosynthetica 36 (1999) 375-387.

[5] Blum A., Photosynthesis and transpiration in leaves and ears of wheat and barley varieties, J. Exp. Bot. 36 (1985) 432-440.

[6] Bort J., Febrero A., Amaro T., Araus J.L., Role of awns in ear wateruse efficiency and grain weight in barley, Agronomie 2 (1994) 133139.

[7] Cantero-Martínez C., Villar J.M., Romagosa I., Fereres E., Growth and yield responses of two contrasting barley cultivars in a Mediterranean environment, Eur. J. Agron. 4 (1995) 317-326.

[8] Ceccarelli S., Yield potential and drought tolerance of segregating populations of barley in contrasting environments, Euphytica 36 (1987) 265-273.

[9] FAO (Food and Agriculture Organization of United Nations), FAO global information and early warning system on food and agriculture world food program, FAO/WFP crop and food supply assessment mission to the kingdom of Jordan, FAO, Rome, 1999.

[10] González A., Martín I., Ayerbe L., Barely yield in water-stress conditions. The influence of precocity, osmotic adjustment and stomatal conductance, Field Crop Res. 62 (1999) 23-34.

[11] Gunasekera D., Santakumari M., Glinka Z., Berkowitz G.A., Wild and cultivated barley genotypes demonstrate varying ability to acclimate to plant water deficits, Plant Sci. 99 (1994) 125-134.

[12] Herzog H., Olszewski A., A rapid method for measuring freezing resistance in crop plants, J. Agron. Crop Sci. 181 (1998) 71-79.

[13] Jamieson P.D., Francis G.S., Wilson D.R., Martin R.J., Effects of water deficits on evapotranspiration from barley, Agr. Forest Meteorol. 76 (1995) 41-58.

[14] Jamieson P.D., Martin R.J., Francis G.S., Wilson D.R., Drought effects on biomass production and radiation-use efficiency in barely, Field Crop Res. 43 (1995) 77-86.

[15] Matouškova M., Bartoškova H., Nauš J., Novatný R., Reaction of photosynthetic apparatus to dark desiccation sensitivity detected by the induction of chlorophyll fluorescence quenching, J. Plant Physiol. 155 (1999) 399-406. 
[16] Nauš J., Kuropatwa R., Klinkovský T., Ilík P., Lattová J., Pavlová Z., Heat injury of barley leaves detected by the chlorophyll fluorescence temperature curve, Biochim. Biophys. Acta 1101 (1992) 359-362.

[17] Ney B., Duthion C., Ture O., Phonological responses of pea to water stress during reproductive development, Crop Sci. 34 (1994) 141-146.

[18] Rawson H.M., Begga A.K., Bremmer P.M., Aspects of adaptation by wheat and barley to soil moisture deficits, Aust. J. Plant Physiol. 4 (1977) 389-401.

[19] Sánchez-Díaz M., García J.L., Antolín M.C., Araus J.L., Effects of soil drought and atmospheric humidity on yield, gas exchange, and stable carbon isotope composition of barley, Photosynthetica 40 (2002) 415-421.

[20] SAS Institute, The SAS System for Windows 6.12, SAS Inst., Cary, NC, USA, 1996.

[21] Sayed O.H., Chlorophyll fluorescence as a tool in cereal crop research, Photosynthetica 41 (2003) 321-330.
[22] Smiciklas K.D., Mullen R.E., Carlson R.E., Knapp A.D., Soybean seed quality response to drought stress and pod position, Agron. J. 84 (1992) 166-170.

[23] Smith M.A., Spomer L.A, Shibli R.A., Knight S.L., Effect of $\mathrm{NaCl}$ salinity on miniature Dwarf Tomato Micro-Tom. II. Shoot and root growth responses, fruit production and osmotic adjustment, J. Plant Nutr. 15 (1992) 2329-2341.

[24] Voltas J., van Eeuwijk F.A., Sombrero A., Lafarga A., Igartua E., Romagosa I., Integrating statistical and ecophysiological analyses of genotypes by environment interaction for grain filling of barley: I. Individual grain weight, Field Crop Res. 62 (1999) 63-74.

[25] Wells S.A., Dubetz S., Reaction of barley varieties to soil water stress, Can. J. Plant Sci. 46 (1966) 507-512.

[26] Westgate M.E., Water status and development of the maize endosperm and embryo during drought, Crop Sci. 34 (1994) 76-83. 